\title{
Management of Patients with Neurotrauma by Trauma Surgeons: Need of the Hour
}

\author{
Amulya Rattan ${ }^{1}$ Subodh Kumar ${ }^{2}$ Amit Gupta² \\ ${ }^{1}$ Department of Trauma Surgery and Critical Care, All India Institute \\ of Medical Sciences, Rishikesh, Rishikesh, Uttarakhand, India \\ 2Division of Trauma Surgery and Critical Care, Department of \\ Surgical Disciplines, JPN Apex Trauma Center, All India Institute of \\ Medical Sciences, New Delhi, India
}

Indian J Neurotrauma 2019;16:82-85

\author{
Biplab Mishra² Sushma Sagar ${ }^{2}$
}

\begin{abstract}
Keywords

- neurotrauma

- trauma surgeon

- emergency neurosurgery

- neurosurgeon scarcity

- general surgeon neurotrauma
\end{abstract}

\begin{abstract}
Address for correspondence Sushma Sagar, MS, FACS, Division of Trauma Surgery and Critical Care, Department of Surgical Disciplines, JPN Apex

Trauma Center, AllMS, New Delhi, India (e-mail: Sagar.sushma@gmail.com).
\end{abstract}

\section{Introduction}

Neurotrauma is a global public health problem. ${ }^{1}$ In India alone, more than 1 million trauma-related deaths occur annually, of which more than half are attributable to head injury. ${ }^{2}$ In fact, neurologic disability has been called as "hidden epidemic of India." ${ }^{3}$ However, accurate head injury statistics in India are lacking and only estimates can be made by extrapolating individual studies. ${ }^{4}$ Even with conservative estimates, approximately 10 million moderate to severe traumatic brain injuries occur annually in India. ${ }^{2}$

\section{Neurosurgeon: A Scarce Resource}

There are just 1,400 certified neurosurgeons in India, and only 300 new trainees are inducted every year with varying pass percentage. ${ }^{5,6}$ Scarcity of neurosurgeons get compounded by the fact that more than $80 \%$ of India's specialist doctors live in urban India. ${ }^{7}$ A study by Neurological Society of India found that there was not a single neurosciences specialist living in a geographical area covering nearly 934.88 million people. ${ }^{7}$ Therefore, patients of neurotrauma often have to travel hundreds of kilometers to have an expert opinion and management thereof; needless to say, golden hour of trauma is surely lost in this time. $^{7}$

Scarcity of neurosurgeons is not limited to developing world; it is a problem in developed world too. It is a scarcely available resource even in the United States, where only $20 \%$ of population has direct access to a specialist, with one neurosurgeon per 70,000 population. ${ }^{8}$ Traveling time

\section{received}

September 15, 2019

accepted

September 16, 2019 
for a review by neurospecialist is universally long, ranging from few hours in U.S. up to a day in India. ${ }^{7,9}$ A survey of neurotrauma management practices in Japan revealed that less than one-third of specialty centers had neurosurgeons in emergency department; $10 \%$ surgeries and $24 \%$ postoperative care were provided by non-neurosurgeons. ${ }^{10}$ Lack of neurosurgeons even in specialist centers was acknowledged as a limiting factor for implementation of recent guidelines in patient care.

With increasing trauma burden and dubious distinction of maximum road traffic injury mortality in world, Government of India has come up with a plan of building a network of trauma centers across India. ${ }^{11}$ Two hundred and fifteen trauma centers including 15 to 20 level 1 and 50 level 2 centers are proposed and will be requiring 150 to 200 neurosurgeons. Preference of specialists to concentrate in Tier 1 cities may prove to be an impediment in achieving desired results. Hence, provision of trauma surgeons and general surgeons trained in neurotrauma is an important component of building an effective trauma center network. ${ }^{11}$

\section{Neurotrauma Management by Trauma Surgeon}

In such dire need of neurotrauma management and scarcity of neurosurgeons, management of neurotrauma by trauma and general surgeons is the best available option. Management of neurotrauma by non-neurosurgeons is not a new concept. It was recognized as long as 25 years ago that management of neurotrauma does not necessarily require expertise of a neurosurgeon. ${ }^{12}$ A National Trauma Data Bank study found that just $1 \%$ of all trauma patients and $3.6 \%$ of all head injury patients required a craniotomy. ${ }^{13}$ Nonavailability of neurosurgeon in civilian setting must allow a trauma surgeon to do a lifesaving decompressive craniotomy. ${ }^{14}$ Polytrauma patients with associated head injury are preferentially managed by trauma surgeons worldwide, with as-needed and predischarge consultation by neurosurgeons. ${ }^{15}$ In military and warfare settings, availability of neurosurgeon is considered a luxury. In such circumstances, trauma or general surgeon must operate on neurotrauma patients to save a life..$^{15}$ Damage control neurosurgery, a concept forwarded by Rosenfeld, also includes management of neurotrauma by non-neurosurgeons. ${ }^{16}$ Refresher training of just 1 week every 2 years has been recommended to prevent skill attrition and to maintain knowledge abreast with latest developments. ${ }^{15}$ Tele-neurotrauma (management of neurotrauma at remote locations in consultation with experts) is being actively studied with promising results in developed countries. ${ }^{17}$ Besides documented benefits of decreasing unnecessary transfers and increased access to specialist opinion, it is a potential tool for taking neurotrauma services to remote areas by trained trauma and general surgeons with tele-neurosurgery consultations as and when required. Need of "virtual neurosciences care" is also realized in India and has been proposed as a means to offset the heterogeneous distribution of neurospecialist in country. ${ }^{7}$

The possibility of neurotrauma operative management by non-neurosurgeons as a lifesaving measure in austere circumstances has been acknowledged by the Advanced Trauma Life Support program as well. ${ }^{18}$

\section{Learning Curve and Patient Safety}

To be able to safely perform lifesaving surgeries in emergency situations or in austere environment, non-neurosurgeons must acquire sufficient experience in such procedures in civilian setting during peace time. In fact, safety of decompressive craniotomy in the hands of general and orthopaedic surgeons, after attending the neurosurgeon-directed courses, have been proven in many countries. ${ }^{15,19}$ According to the published reports, participants were able to manage warfare neurotrauma operatively after 1 week of intensive course followed by 1-week in-house residency, which included clinical rounds, neurocritical care, and participation in planned and emergency neurosurgical procedures. Safe placement of intracranial pressure (ICP) monitors and ventricular catheters by non-neurosurgeons after training have also been shown by Ko and Conforti with results similar to neurosurgeons. ${ }^{20}$ With regard to learning curve, it has been documented that observation and assistance in five ICP catheter insertion procedures followed by five successful independently performed supervised procedures are adequate to certify a non-neurosurgeon for safe ICP placement. ${ }^{20}$ Techniques for emergency burr hole by non-neurosurgeons, a skill getting obsolete, are still published citing requirement even in developed countries. ${ }^{21}$ There are published reports of successful management of neurotrauma by general surgeons, telementored by the neurosurgeon remotely. Subsequent drop in neurosurgical tele-referrals from telemedicine-enabled centers were attributed to increased confidence among general surgeons in managing neurotrauma independently. ${ }^{7}$ Learning curve for operative procedures of neurotrauma management has been published.

There is enough evidence to support nonoperative management of neurotrauma by general surgeons in other developing countries as well. ${ }^{22}$ Ghimire et al reported operative rate of $2 \%$ in 1,847 neurotrauma patients over 4 years with a mortality of $2.8 \%$, establishing the safety of neurotrauma management by general surgeons in their regional hospital with no neurosurgeon. ${ }^{23} \mathrm{~A}$ recent study from Swedish counties reiterated the safety of their "regional policy" of operative management of neurotrauma by general surgeons citing good postoperative clinical and long-term outcomes. ${ }^{24}$

\section{Indian Scenario}

Operative management of neurotrauma by trauma surgeons is not a new concept in India; Fellow of National Board trainees in trauma surgery are known to have performed sufficient number of craniotomies during training period. ${ }^{25}$ As noted, number and distribution of neurosurgeons in India is not enough to cater majority of the population effectively. ${ }^{7}$ Jai Prakash Narayan Apex Trauma Center under aegis of All India Institute of Medical Sciences, New 
Delhi, India, has taken a lead in this direction and started a 3-year Master of Chirurgic program in trauma surgery and critical care with integrated training in orthopaedic, neurosurgery, plastic surgery, and cardiothoracic trauma in addition to general surgical trauma. Trainees are trained in ICP insertion, neurocritical care, and emergency neurosurgical procedures during their training in neurotrauma for a period of 6 months. This is followed by an exit written examination bearing a question from the subject and viva voce of 20 marks conducted by neurosurgeon. This dedicated and uninterrupted academic program in trauma surgery since 2016 is a testimony to its utility and appeal of this much needed initiative. ${ }^{26}$

Another initiative in pipeline is a proposal for 6-month neurotrauma course for general surgeons, to enable them to provide neurotrauma services at their respective hospitals in tier 2 and 3 cities. Director General of Health Services operational guidelines on capacity building in trauma care in India mandates level 2 trauma centers to be staffed with general surgeons with 6 -months neurotrauma training. ${ }^{11}$

\section{Conclusion}

A "readily available neurosurgeon when needed" is a scarce resource in mainland India, barring metropolitan cities. ${ }^{7}$ In such circumstances, natural savior of neurotrauma patients is the trauma surgeon, who has seamless understanding of multisystem trauma care and is best suited to take call on competing priorities. Skills required for successful neurotrauma management, operative or nonoperative, are essentially those learnt in general surgical residency programs. ${ }^{15}$ Efficacy and safety of this approach has been proved in published literature. ${ }^{22-24}$ Unless we have a prehospital system that can take the "right patient to right place at right time," trauma surgeon is best suited and will have to wear the robes of neurosurgeon to deliver timely care and tackle this "hidden epidemic." 3

\section{Disclosure}

A.R. joined the first batch of M.Ch. in Trauma Surgery and Critical Care program at JPNATC. After completing his training, he is currently affiliated to another upcoming level 1 trauma care facility at AIIMS, Rishikesh.

\section{Funding}

None.

\section{Statement of Approval from All Authors}

All authors certify that they have made substantial contributions to conception, design, analysis, and interpretation of data, drafted the article and revised it critically for important intellectual content, and approve the final version to be published.

\section{Conflict of Interest}

All authors declare that there is no conflict of interest.

\section{References}

1 Neurotrauma. In: WHO Report on Injuries. Available at: https:// www.who.int/violence_injury_prevention/road_traffic/ activities/neurotrauma/en/. Accessed September 5, 2019

2 Maas AI. Traumatic brain injury in India: a big problem in need of data. Neurol India 2017;65(2):257-258

3 Das A, Botticello AL, Wylie GR, Radhakrishnan K. Neurologic disability: a hidden epidemic for India. Neurology 2012;79(21):2146-2147

4 Massenburg BB, Veetil DK, Raykar NP, Agrawal A, Roy N, Gerdin $M$. A systematic review of quantitative research on traumatic brain injury in India. Neurol India 2017;65(2):305-314

5 Gupta A. Challenges in the development of trauma systems in an emerging economy-India. IATSIC Donald Trunkey Oration 2019 delivered on 14/8/2019 at: World Congress of Surgery, 2019, Krakow, Poland

6 NEET seat matrix. Available at: http://mcc.nic.in/MCCSS/ SEatMatrix.aspx. Accessed September 5, 2019

7 Ganapathy K. Distribution of neurologists and neurosurgeons in India and its relevance to the adoption of telemedicine. Neurol India 2015;63(2):142-154

8 Orrico K. Ensuring an Adequate Neurosurgical Workforce for the 21st Century, Statement of the American Association of Neurological Surgeons, American Board of Neurological Surgery, Congress of Neurological Surgeons, Society of Neurological Surgeons Before the Institute of Medicine; December, 2012. Available at: https://www.cns.org/sites/ default/files/legislative/NeurosurgeryIOMGMEPaper121912. pdf. Accessed September 5, 2019

9 Shortage of Neurologists Predicted to Worsen. April 26, 2013 , Science News, Parkinson's Disease Foundation, Inc.; 2014. Available at: http://www.pdf.org/en/science_news/release/ pr_1367003841. Accessed September 5, 2019

10 Suehiro E, Fujisawa H, Koizumi H, et al. Survey of current neurotrauma treatment practice in Japan. World Neurosurg 2011;75(3-4):563-568

11 Capacity building for developing trauma care facilities on national highways. Operational guidelines. Available at: https://dghs.gov. in/WriteReadData/userfiles/file/Operational_Guidelines_Trauma. pdf. Accessed September 5, 2019

12 Mauer U, Waldbaur H, Schneider R, Oldenkott P. Die interdisziplinäre Versorgung schwerer Kopfverletzungen. Wehrmed Mschr 1995;39:160-163

13 Esposito TJ, Reed RL II, Gamelli RL, Luchette FA. Neurosurgical coverage: essential, desired, or irrelevant for good patient care and trauma center status. Ann Surg 2005;242(3):364-370, discussion 370-374

14 Treacy PJ, Reilly P, Brophy B. Emergency neurosurgery by general surgeons at a remote major hospital. ANZ J Surg 2005;75(10):852-857

15 Mauer UM, Kunz U. Management of neurotrauma by surgeons and orthopedists in a military operational setting. Neurosurg Focus 2010;28(5):E10

16 Rosenfeld JV. Damage control neurosurgery. Injury 2004;35(7):655-660

17 Latifi R, Olldashi F, Dogjani A, Dasho E, Boci A, El-Menyar A. Telemedicine for neurotrauma in Albania: initial results from case series of 146 patients. World Neurosurg 2018;112:e747-e753

18 Head Trauma. In: Advanced Trauma Life Support Student Course Manual. 10th ed. Chicago, IL: American College of Surgeons; 2018:102-127

19 Rinker CF, McMurry FG, Groeneweg VR, Bahnson FF, Banks KL, Gannon DM. Emergency craniotomy in a rural Level III trauma center. J Trauma 1998;44(6):984-989

20 Ko K, Conforti A. Training protocol for intracranial pressure monitor placement by nonneurosurgeons: 5-year experience. J Trauma 2003;55(3):480-483. 
21 Wilson MH, Wise D, Davies G, Lockey D. Emergency burr holes: "How to do it" Scand J Trauma Resusc Emerg Med 2012;20(1):24

22 Gbalipre FB, Cliford OE. Pattern and outcome of management of head injury by general surgeons at the accident and emergency department of the Niger delta university teaching hospital Okolobiri, Bayelsa state of Nigeria. Palgo J Med Sci 2014;1(1):1

23 Ghimire P, Yogi N, Acharya GB. Management of head injury by general surgeons in a general hospital. Nepal J Med Sci 2012;1(1):19-22
24 Fischerström A, Nyholm L, Lewén A, Enblad P. Acute neurosurgery for traumatic brain injury by general surgeons in Swedish county hospitals: a regional study. Acta Neurochir (Wien) 2014;156(1):177-185

25 Available at: http://apexmedicalacademy.com/CVOfDrSanjayShah.aspx. Accessed September 5, 2019

26 MCh Trauma Surgery \& Critical Care program AIIMS New Delhi. Available at: https://www.aiimsexams.org/pdf/ Prospectus\%20DMMCH\%20Jan-2020\%20-\%20(2.9.2019).pdf. Accessed September 5, 2019 